\title{
Surgical and radiologic anatomy 2008/2009
}

\section{F. Duparc}

Published online: 31 January 2009

(C) Springer-Verlag 2009

Dear colleagues,

2008 has been a new very successful year for our journal SRA. The number of submitted manuscripts continued to increase (353 in 2008, +34\%), coming from 45 countries. Our publisher, Springer, had proposed eight issues per year since 2007, and this number will be increased to ten issues per year in 2009. This represents a hard job for the editorial team, and for the reviewers. We are very thankful to all of them for their very appreciated collaboration. Due to the quality of the analysis and the high level of the proposed revisions, the authors received interesting suggestions and various opinions for completing their manuscripts. This development of our journal SRA has been really nice for its 30th year!

We aim to warmly thank Professor J. R. Ortale, Brazil, for his intensive and very appreciated participation to the international board of SRA since 1995, until he retired in 2008.

It is our honor to thank Professor Pierre Lasjaunias, France, and to celebrate his memory. His sudden death on
June 30th, 2008, has been terrible for the international community of anatomists, neuroradiologists, and researchers. His contribution to the knowledge of the anatomy, the medical imaging, and the understanding of brain vessels and their pathologies has been considerable.

2009 will be the year of the I.F.A.A. congress in August (Cape Town, South Africa), and of the E.A.C.A. congress in September (Istanbul, Turkey). These meetings will be certainly very successful, and large numbers of participants are expected in each of them.

The field of the research in clinical anatomy is large, and provides an increasing panel of scientific topics, from the fundamental descriptive anatomy and its clinical relevance in medical practice to the development of new techniques and technologies.

The complete editorial team wishes you a very happy New Year.

Erratum: in the list of reviewers of the published manuscripts in the 2007 issues, Prof. B. Sénécail had been omitted. 